\title{
THE IMPLICATIONS OF TEMPORAL PATTERNS FOR THE PROSODY OF BOUNDARY SIGNALING IN CONNECTED SPEECH
}

\author{
Zita McRobbie-Utasi \\ Department of Linguistics, Simon Fraser University \\ Burnaby, British Columbia. V5A 1S6. Canada. \\ zita_mcrobbie@sfu.ca
}

\begin{abstract}
The objective of the study reported on here is to further examine the implications of recent research concerning the status of duration in boundary signaling in languages in which duration plays a contrastive role in the suprasegmental system. The issues addressed here are (i) the extent to which durational patterns in the temporal organization of connected speech differ from those observed in controlled experiments, and (ii) how the realization of timing strategies can be related to the prosodic manifestations of boundary signaling.

It will be argued that the four timing strategies in Skolt Sámi (a Finno-Ugric language) that were observed during a series of controlled experiments appear to have a clearly noticeable hierarchy in terms of their occurrence in connected speech. This study will evaluate the characteristics of this hierarchy. Concerning the second issue it will be claimed that the analysis described has produced results which correspond with the implications of other recent research [2], [4]: i.e. showing that languages with contrastive duration tend not to utilize duration for additional functions in the grammar, in this case boundary signaling.
\end{abstract}

\section{INTRODUCTION}

In a series of earlier studies I reported on the durational patterns characteristic of Skolt Sámi [5], [7], [9]. It was claimed there that durational ratios rather than absolute durational values are significant in the signaling of different structural types in that language. These tendencies were examined and analyzed in disyllabics spoken in citation forms in a sentence frame; thereafter the validity of these findings were tested in larger grammatical units during the course of a controlled experiment, reported on in [6]. In that report reference was made to four timing strategies noticed in the realization of durational distribution of three sentences occurring in a different order within the paragraph. On the basis of the six configurations recorded by two speakers of Skolt Sámi the following four strategies were observed: (i) employing (or not, as the case may be) vowel reduction (or vowel drop) depending on the distance from the boundary of the paragraph; (ii) shorter absolute durations achieved by keeping the characteristic durational ratios constant, (iii) shorter word durations in paragraph-final sentences; (iv) consistently shorter pause durations in paragraph-final sentences.

The characteristics of the temporal patterns resulting from the application of these timing strategies, during the course of a series of controlled experiments, served as a point of departure for the present study. Here the same phenomena were observed in conversational speaking mode and were related to the prosody of boundary signaling. It was found that in this speaking mode a definite hierarchy seems to be apparent, rendering the option not to employ vowel reduction (or vowel drop) the least relevant among the available four timing strategies. It is clear that the maintaining of the characteristic durational ratios occupies the first place in that hierarchy. This consistent effort to keep significant durational patterns unchanged overrides observable strategies for significant durational decrease in positions close to boundaries.

It can be said with certainty that the maintaining of characteristic durational ratios is to be considered an essential feature of Skolt Sámi prosody. In recent studies on articulatory simplicity associated with speaking modes where articulatory precision appears to function to a considerably lesser degree it has been stated that linguistically significant parameters tend to remain stable [2]. The experiment described below provides support for such a theory by demonstrating that even though durational changes are evident (i.e. absolute durational values vary), significant ratio values tend to remain stable.

\section{METHOD AND EXPERIMENT}

The material analyzed here consists of audio recordings of spontaneous conversation by two native speakers of the language who had previously participated in the controlled experiment. Results of the controlled experiment served as reference points for (i) absolute durational values of the relevant segments occurring in the disyllabics in question, and (ii) ratio values. The segments considered for durational comparison with the values obtained in the controlled experiment were the first syllabic vowel and the consonant(s) following this vowel. Disyllabic stress-groups in Sámi constitute a basic quantity unit [1], [3] where durational patterns showing clear interdependencies ensure coherence between the two syllables within this rhythmic unit [5], [7], [8].

A total of 140 utterances was analyzed, 84 and 56 respectively for each speaker. The materials selected for examination consisted of those sections of spontaneous conversation in which certain durational targets could be identified, i.e. paragraphs. The analysis is a follow-up of a similar experiment reported on in [8]. This present study differs from the one referred to in two respects: (i) durational patterns were examined on the basis of a more extended corpus, and (ii) all timing strategies associated with larger grammatical units were analyzed and the hierachy of their application in spontaneous speech were examined. 
For the controlled experiment recordings were made on a Scully Full-Track Broadcast Machine while for the spontaneous conversation a Sony TCM-500 tape recorder was employed. Both audio recordings were analyzed by the software Signalyze (Version 3.12) with a Macintosh computer.

\subsection{Durational measurements of disyllabics in citation form}

Disyllabics placed in a sentence frame were spoken by the two speakers with the objective of obtaining durational values of the first syllabic vowel and the consonant(s) following it. All disyllabics that may undergo vowel reduction (or vowel drop) were examined in five groups depending on the quantitative status of the intervocalic consonants. These structural types are the following: Type 1 (containing a long geminate), Type 2 (containing a long consonant cluster), Type 3 (containing a single consonant), Type $4 \mathrm{a}$ (containing a short geminate sonorant) and Type $4 \mathrm{~b}$ (containing a short geminate obstruent). The following two tables summarize durational values measured (i) when the second syllable contained a full vowel, and (ii) when the second syllabic vowel was substantially reduced (by $60-80 \mathrm{msec}$ ) or when it was dropped.

Figure 1 demonstrates the ratios between the first syllabic vowel and the consonant(s) following that vowel. As may be seen from the ratio values, there is little change that can be registered in connection with absolute durational changes. The noticeable difference in the ratios of Type 3 disyllabics has no relevance to the present discussion: an interpretation of the implications involved there has been discussed in [5] and [9].

\subsection{Durational measurements of disyllabics occurring in paragraph- final sentences in spontaneous conversation}

The measurement values as shown in the two tables and the above figure will be referred to when compared to (i) absolute durational changes, and (ii) ratio values manifested in the recordings of spontaneous conversations between the two speakers. As indicated above (and discussed in [6] in detail], the effect of one of the timing strategies observed was to reduce duration both in the disyllabics (reduced duration consequently occurring in the relevant segments in these disyllabics) and in the pauses, both of these durational reductions being most evident in paragraph-final sentences. We may add that while the relevant disyllabics had an average duration in citation forms of between 550 and $720 \mathrm{msec}$ (depending on the structural type), the disyllabics analyzed in spontaneous conversation averaged in duration between 145 and $290 \mathrm{msec}$. Tables 3 and 4 summarize the durational measurements obtained for disyllabics in these much reduced forms together with the respective ratio values.

The two tables below testify to the tendency to maintain significant durational ratios in the conversational speaking mode associated with a significant decrease in absolute durational values in those disyllabics occurring in a paragraphfinal sentence. These tendencies are summarized in Figure 2.

\begin{tabular}{|lccrc|}
\hline \multicolumn{1}{l}{ Type } & \multicolumn{2}{l}{ V1 } & \multicolumn{2}{l|}{ C } \\
& $\overline{\bar{x}}$ & SD & $\overline{\mathrm{x}}$ & SD \\
1 & 175 & 30 & 248 & 31 \\
2 & 153 & 22 & 366 & 38 \\
3 & 299 & 23 & 87 & 14 \\
$4 \mathrm{a}$ & 238 & 28 & 163 & 30 \\
$4 \mathrm{~b}$ & 238 & 28 & 197 & 27 \\
5 & 225 & 26 & 174 & 24 \\
\hline
\end{tabular}

Table 1: Durational measurements of disyllabics in Skolt Sámi with a full vowel in the second syllable

\begin{tabular}{|llrrr|}
\hline \multicolumn{3}{l}{ Type } & \multicolumn{3}{c|}{ V1 } \\
& $\overline{\mathrm{x}}$ & $\mathrm{SD}$ & $\overline{\mathrm{x}}$ & $\mathrm{SD}$ \\
1 & 207 & 33 & 287 & 31 \\
2 & 185 & 28 & 400 & 32 \\
3 & 363 & 34 & 92 & 10 \\
$4 \mathrm{a}$ & 265 & 30 & 199 & 30 \\
$4 \mathrm{~b}$ & 269 & 30 & 233 & 33 \\
5 & 258 & 30 & 215 & 28 \\
\hline
\end{tabular}

Table 2: Durational measurements of disyllabics in Skolt Sámi with a reduced vowel or $\emptyset$ in the second syllable

\begin{tabular}{|lrrrrl|}
\hline \multicolumn{3}{l}{ Type } & \multicolumn{5}{c}{ V } & \multicolumn{3}{c|}{ C/C } \\
& $\overline{\mathrm{x}}$ & $\mathrm{SD}$ & $\overline{\mathrm{z}}$ & $\mathrm{SD}$ & \\
1 & 102 & 32 & 134 & 26 & 0.76 \\
2 & 81 & 27 & 179 & 34 & 0.45 \\
3 & 177 & 35 & 67 & 21 & 2.64 \\
$4 \mathrm{a}$ & 140 & 31 & 90 & 30 & 1.55 \\
$4 \mathrm{~b}$ & 156 & 37 & 131 & 34 & 1.19 \\
5 & 150 & 35 & 120 & 36 & 1.25 \\
\hline
\end{tabular}

Table 3: Segment durations and $\mathrm{V} / \mathrm{C}$ ratios in spontaneous speech with a full vowel in the second syllable

\begin{tabular}{|lrrrrl|}
\hline \multicolumn{1}{l}{ Type } & \multicolumn{3}{c}{ V } & \multicolumn{3}{l|}{ C } & V/C \\
& $\overline{\mathrm{x}}$ & $\mathrm{SD}$ & $\overline{\mathrm{x}}$ & $\mathrm{SD}$ & \\
1 & 132 & 37 & 160 & 34 & 0.82 \\
2 & 110 & 29 & 199 & 37 & 0.55 \\
3 & 203 & 35 & 70 & 32 & 2.9 \\
$4 \mathrm{a}$ & 164 & 30 & 121 & 29 & 1.35 \\
$4 \mathrm{~b}$ & 177 & 29 & 156 & 35 & 1.13 \\
5 & 179 & 36 & 145 & 34 & 1.23 \\
\hline
\end{tabular}

Table 4: Segment durations and V/C ratios in spontaneous speech with no vowel in the second syllable

\subsection{A comparison of the employment of optional vowel reduction in the controlled experiment vs. spontaneous conversation}

While enumerating strategies apparent in the temporal organization of a paragraph in the controlled experiment [4] it was observed that employment of this optional rule was more 
evident in sentences of paragraph-final position. When the same sentence occurred in first position, the percentage of vowels not undergoing reduction was considerably higher. It was thus justified to hypothesize that the optionality of vowel reduction was utilized as one of the ways to keep to a durational target associated with the paragraph. The fact that in paragraph-final position disyllabics occurring in the sentence almost without exception underwent vowel reduction strongly suggests that vowel reduction is one of the timing strategies that speakers of Skolt Sámi utilize.

When encountering the occurrences of vowel reduction in spontaneous speech it was found that very little difference exists in this regard between disyllabics in paragraph-initial and paragraph-final positions -- vowel reduction, or more frequently vowel drop, occurs in disyllabics subject to this optional rule.

Table 6 summarizes this observation, showing the percentages (together with the total of relevant disyllabics) of the employment or non-employment of the vowel reduction (or vowel drop) rule in sentences of paragraph-initial and paragraph-final position in both the controlled experiment and spontaneous conversation.

\begin{tabular}{|c|c|c|c|c|}
\hline \multirow[t]{2}{*}{ Sentence position } & & Controlled Experiment & \multicolumn{2}{|c|}{ Spontaneous Conversation } \\
\hline & percent & number & percent & number \\
\hline paragraph-initial & 14 & 74 & 98 & 167 \\
\hline paragraph-final & 89 & 74 & 100 & 167 \\
\hline
\end{tabular}

Table 5: Occurrences of vowel reduction (or vowel drop)

\section{V/C Ratios}

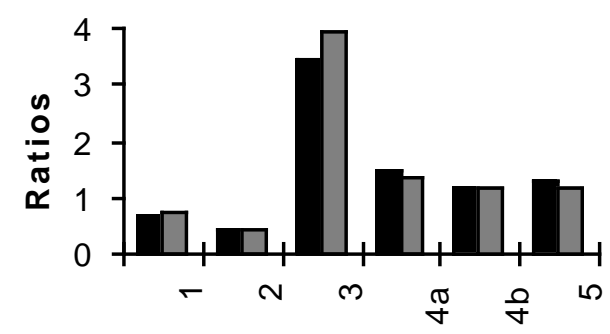

STRUCTURAL TYPES

V/C /full V) $\quad$ प V/C (red. V or $\varnothing)$

Figure 1: Mean V/C ratios of disyllabics

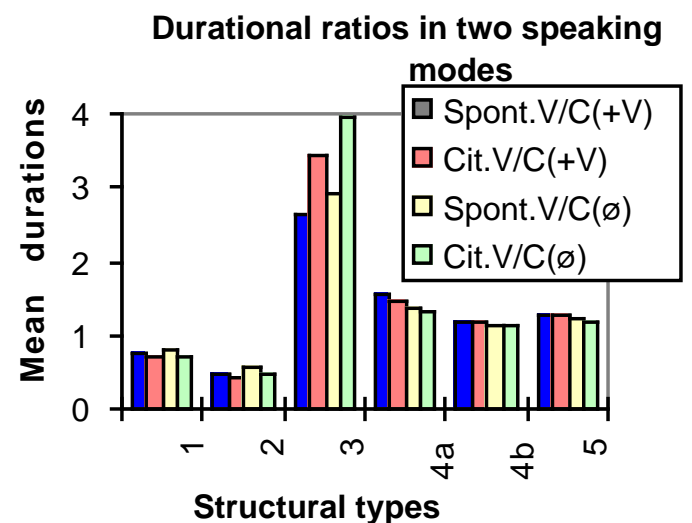

Figure 2: A comparison of segment durational ratios in spontaneous speech with those in citation form. 


\section{CONCLUSIONS}

The implications of the temporal patterns in spontaneous conversation point towards recognizing a definite hierarchy with regard to the employment of the four strategies referred to above that were attested in the controlled experiment.

It seems evident that the maintaining of durational ratios occupies first place in the hierarchy. This conforms to the assumptions of relevant research concerning the fact that in the conversational speaking mode only those articulatory parameters undergo significant change that do not affect linguistically relevant prosodic arrangements in the language

\section{REFERENCES}

1. Bergsland, K. Røros-Lappisk grammatikk. Oslo: Instituttet for Sammenlignende Kulturforskning. 1946.

2. Engstrand, O. \& D. Krull. "Durational correlates of quantity in Swedish, Finnish and Estonian: Crosslanguage evidence for a theory of adaptive dispersion," Phonetica 51, 80-91. 1994.

3. Itkonen, E. Struktur und Entwicklung der ostlappischen Quantitätssysteme. Mémoires de la Société FinnoOugrienne 88. Helsinki: Suomalais-ugrilainen Seura. 1946.

4. Lehiste, I. \& R. Fox. "Perception of prominence by Estonian and English listeners," Language and Speech 35, 419-434. 1992.

5. McRobbie-Utasi, Z. "Durational ratios of disyllabics in relation to the syllable boundary in Skolt Sámi," in Proceedings of the XIIth International Congress of Phonetic Sciences, Aix-en-Provence, France. Vol. 3, 306-309. 1991.

6. McRobbie-Utasi, Z. "Timing strategies within the paragraph," in Proceedings of the 1994 International Conference on Spoken Language Processing, Yokohama, Japan. 382-386. 1994.
-- here, the significant durational ratios. Thus support is given to the hypothesis concerning the non-availability of duration for boundary-signalling in languages -- such as the one in the present study -- in which it plays a significant role in the prosodic system. Located at the other end of the hierarchy would appear to be the timing strategy involving vowel reduction (or vowel drop). That the strategy involving the employing or non-employing of this available option, depending on the distance of boundaries -- so apparent in the controlled experiment -- plays no such part in spontaneous conversation in Skolt Sámi, indicates that different temporal strategies are associated with different speaking modes.
7. McRobbie-Utasi, Z. "The maintaining of durational distinctions: Patterns and consequences," in University of Toronto Working Papers in Linguistics. 349-360. 1995.

8. McRobbie-Utasi, Z. "The maintaining of durational ratios in quantity distinctions in conversational speech," in Proceedings of the XIIIth International Congress of Phonetic Sciences, Stockholm. 166-9. 1995.

9. McRobbie-Utasi, Z. "An acoustical analysis of durational interdependencies in Skolt Sámi: Theoretical implications," in Proceedings of the Eighth International Finno-Ugric Congress. Jyväskylä. Vol.3, pp. 28-32. 1995. 